\title{
What Is the Issue with Internet Acceptance among Elderly Citizens? Theory Development and Policy Recommendations for Inclusive E-Government*
}

\author{
Bjoern Niehaves and Ralf Plattfaut \\ Westfälische Wilhelms-Universität Münster, European Research Center for Information \\ Systems, Leonardo-Campus 3, 48149 Münster \\ \{bjoern.niehaves, ralf.plattfaut\} dercis.uni-muenster.de
}

\begin{abstract}
Digital divide is still a big topic in information systems and egovernment research. In the past, several tracks and workshops on this topic existed. As information technology and especially the internet become more and more important governments cannot ignore the fact that elderly citizens are excluded from the benefits related to internet usage. Although e-Inclusion programmes and initiatives changed over the years and, moreover, although the amount of e-Inclusion literature is constantly growing, there is still no thorough understanding of potential factors influencing private internet usage. Hence, in this study we identify important influencing factors based on the literature on technology acceptance and digital divide. We develop a model based on these factors and test it against comprehensive survey data $(n=192)$. Our theoretical model is able to explain more than $70 \%$ of the variation in private internet usage. We derive policy recommendations based on the results and discuss implications for future research.
\end{abstract}

Keywords: Digital Divide, e-Inclusion, UTAUT, Quantitative Study.

\section{Introduction}

Today's western societies face two common trends: First, today's societies around the world tend to "age" or "grey" [26]. The share of population older than 65 years is $15.9 \%$ and will rise up to $25.9 \%$ by 2050 . Second, the importance of information, information processing, and communication is constantly growing. This phenomenon has been condensed to the term information society [34, 15].

Societal aging bears several risks for an information society. On the one hand, an increasing share of elderly citizens results in problems for local governments such as fiscal stress and increasing expenditure on health care or pensions [19]. On the other hand, large parts of the population are excluded from the information society. They neither have access nor skills to use modern media like the internet. A digital divide among on-liners and non-liners exists [22]. Especially senior citizens are often excluded from modern technology $[6,4]$.

The authors are grateful to the financial support of this research by the VolkswagenFoundation. 
However, governments want to make use of the growing importance of ICT. Especially local authorities can enhance the effectiveness and efficiency of their processes and organisational structure using ICT and, by this, lever their productivity to a new level (electronic or transformation government [31]). Moreover, government agencies can provide their services "online" and support them by means of ICT. However, in a digitally divided world the non-liners are excluded from the benefits of ICT supported governmental services. The European Union recognised both the importance of ICT and the existence of a digital divide. Therefore, the ministers of the member states of the EU called for an inclusive information society and declared to focus on multiple goals to reach this aim [21]. This was also captured by the cabinet office of the United Kingdom which called for tackling "overall issues of digital inclusion" [9] and works "towards achieving equitable access to new technology and remove the barriers to take-up" [10]. Both define electronic inclusion (e-inclusion) as an integral part of (especially local) governmental policies.

Projects to bridge the digital divide have a long history. First generation projects included grants to provide more senior citizens with computers [16], free internet access at local libraries or comparable centres, as well as internet courses specially designed for elderly people [32]. However, technology acceptance research suggests several other barriers that could be tackled by governmental e-inclusion projects. The Unified Theory of Acceptance and Use of Technology (UTAUT) suggests that next to Effort Expectancy, which is tackled by internet courses, and Facilitating Conditions, which are (among others) established through the provision of access, Performance Expectancy and the social milieu play an important role in explaining usage behaviour. Hence, it is doubtable whether the mere provision of computer courses or free internet access are sufficient to reach an inclusive information society. Moreover, there is the possibility that the group of non-liners is fragmented and that different measures should be established for different groups. Hence, this study aims at clarifying the following research questions:

RQ1 How can we explain the private internet usage and non-usage of senior citizens?

RQ2 What are important factors for senior citizens' usage and non-usage of the internet?

RQ3 Does an extension of UTAUT using more moderating variables from the digital divide literature provide a benefit in explaining private internet usage among the elderly?

RQ4 What can practitioners learn from a more comprehensive view on senior citizens' internet usage?

To answer this question, we quantitatively study the citizens of age 50 or higher in a medium-sized city in Western Europe. We created a questionnaire based on the theoretical background of the UTAUT [47] and the Digital Divide literature [48, 45, 2 , 5]. This questionnaire was handed out to more than 3,000 randomly chosen inhabitants. In sum, we received 192 questionnaires from respondents aged 50 or higher. For data analysis, we use the partial least squares (PLS) method [35].The paper is structured as follows. In the next section, we will present some theoretical background. Afterwards, we will develop our research model based on the UTAUT and Digital Divide literature. In section four, we will present our research 
methodology in detail. The results are presented in section five. We will discuss them in terms of relevance for theory and practice in section six. The last section is concerned with limitations, conclusions, and future research.

\section{Theoretical Background}

E- and T-government have been established as a main concept in government change processes and integrates technical, social, and organisational themes [31, 42]. Being ready to change and improve has become a necessity for public administrations in order to cope with increased demands in a complex change environment. Exploitation of benefits realised by electronic government (e-government) is the essential part of this strategy. Being part of this agenda, in its transformation government implementation plan, the Cabinet Office [10, page 4] acknowledges that the exploitation of the full potential of electronic service delivery includes making wider use of online provision in order to make services more accessible to the public (see for instance, online centres [9, 36]). However, research discusses age-related factors and demographic trends that might counteract these efforts. Societal aging is a major demographic trend in industrialised societies. Hauser \& Duncan [28, p2] define demography as "the study of the size, territorial distribution, and composition of population, changes therein, and the components of such changes, which may be identified as natality, mortality, territorial movement (migration), and social mobility (change of status)." Three major factors constitute the development of demography: a) fertility, b) mortality, and c) migration. In this context, especially fertility and mortality have undergone significant changes in most industrialised countries over the last decades. On the one hand, fertility has been declining due to, for instance, changed life models or family planning [38]. On the other hand, regarding mortality, life expectancy has increased substantially because of, e.g., improved medical care. For instance, between 1995 and 2003, life expectancy at birth in European countries, now being 78 years on average for men and 83 for women, went up by an average of 3 months each year for men and 2 months for women [17]. As a consequence, societal aging (synonym: population aging) has established itself as a long-term trend that will continue for generations to come. Demographic projections indicate that the group of 65 years and older will continue to constitute a growing share of population. For instance, at present, 14 of the world's 15 "oldest" countries in terms of percentage of people aged 65 or older, are in Europe, while Japan heads this ranking [40]. In 2050, for the European Union (EU) the population share of those aged 65 and more is projected to increase to $29.9 \%$ and for Japan to $39.6 \%$. Similarly, in the United States (USA) and Canada, the population share of those aged 65 and more, is estimated to increase to $21 \%$ and $23.7 \%$ respectively. While the demographic trend of societal aging is particularly distinct in more developed nations, less and least developed nations also share this general tendency.

Societal aging poses challenges to the development of t-government and einclusion strategies. One of these challenges is the (here: age-related) digital divide $[45,2,5,3]$, in this context understood as an emerging polarisation phenomenon in society, creating a gap between those who do have access to and use the potentialities 
of ICTs, and those who do not [18]. The demographic gap refers, amongst others, to the fact that senior people often do not use ICT on a regular basis $[6,39,5]$. The reasons for this gap results from a multitude of challenges which senior people often face. These include for instance isolation, physical disabilities, or low retirement pension [33]. Disabilities can debar people from actively using information technology. For the usage of online services the most important disabilities to consider are visual handicaps, cognitive defects and limitations of motor skills. Geographical differences refer to gaps in ICT usage between different regions. Socioeconomic gaps include differences in occupation, income and education whereas ethnical and cultural gaps identify barriers in the ICT usage of migrants and ethnical minorities. Here, e-inclusion focuses on the elimination of these barriers for the use of ICT. The declaration of Riga gives the following definition of E-inclusion: "'eInclusion' means both inclusive ICT and the use of ICT to achieve wider inclusion objectives. It focuses on participation of all individuals and communities in all aspects of the information society. E-inclusion policy, therefore, aims at reducing gaps in ICT usage and promoting the use of ICT to overcome exclusion, and improve economic performance, employment opportunities, quality of life, social participation and cohesion." [21, p. 1] The main focus of e-inclusion is on creating accessible services over ICT. This effort can be divided into accessibility and usability aspects [33]. Accessibility means the possibility for handicapped people to access the relevant service (e.g. Braille support). Usability focuses on the user-friendliness of a webservice (e.g. easy discovery and fast navigation within a website [20]).

\section{Research Model}

Against the background of our research objective, our research model is informed by two streams of research: acceptance and use of technology as well as digital divide research. As for research on acceptance and use of technology, Venkatesh et al. [47] undertake a comprehensive comparison of theories in this field in order to develop their UTAUT. The authors provide evidence that, for the case of information technology acceptance, their model shows best explanatory power, comparing with, for instance, the theory of reasoned action [24, 23], the technology acceptance model [13], or the theory of planned behaviour [43]. Therefore, we will apply UTAUT for explaining behavioural intention towards personal use of the internet (BI) as well as for explaining use behaviour regarding personal internal usage (USE). Here, Venkatesh et al. [47] provide evidence for the influence of the following independent variables: Performance Expectancy (PE), Effort Expectancy (EE), Social Influence (SI), and Facilitating Conditions (FC). As for the representation of the digital divide perspective, four additional variables were included in our model: education [45,2,5], gender $[27,7,2,5]$, income $[48,7,2,5]$, and migration background [2,5]. Here, we argue - in line with other studies - that these factors moderate the relationships described in the original UTAUT model. ${ }^{1}$

${ }^{1}$ Please contact the author for information on the constructs, questions, measures, and their roots. 
According to studies of technology acceptance, specifically UTAUT, and taking into account digital divide research, we formulate the following hypotheses in order to explain behavioural intention towards personal use of the internet:

1) On the influence of Performance Expectancy:

Hla: Performance Expectancy will positively influence Behavioural Intention.

$H 1 b$ : The influence of Performance Expectancy on Behavioural Intention will be moderated by education, gender, income, and migration background (digital divide variables).

2) On the influence of Effort Expectancy:

H2a: Effort Expectancy will positively influence Behavioural Intention.

H2b: The influence of Effort Expectancy on Behavioural Intention will be moderated by education, gender, income, and migration background (digital divide variables).

3) On the influence of Social Influence:

H3a: Social Influence will positively influence Behavioural Intention.

H3b: The influence of Social Influence on Behavioural Intention will be moderated by education, gender, income, and migration background (digital divide variables).

As for the explanation of internet personal use behaviour we formulate the following hypotheses based on Venkatesh et al. [47] as well as digital divide research:

4) On the influence of Behavioural Intention:

H4: Behavioural Intention will positively influence Use Behaviour.

5) On the influence of Facilitating Conditions:

H5a: Facilitating Conditions will positively influence Use Behaviour.

H5b: The influence of Facilitating Conditions on Use Behavioural will be moderated by education, gender, income, and migration background (digital divide variables).

We assume that the original UTAUT has significant power to explain variations in behavioural intention towards personal internet use and in use behaviour. Moreover, we assume that taking into account insights from digital divide research, specifically variables such as education, gender, income, and migration background, will further increase the explanatory power of the model. We thus seek to apply UTAUT for studying personal internet usage and to extend the model by integrating insights from digital divide research.

\section{Research Methodology}

Data collection phase. Before the data collection phase, we constructed a questionnaire according to the research model presented above. Here, we applied well established constructs and items for measurement. Also, we conducted a pilot study with 7 respondents for the purpose of questionnaire validation. It led to positive feedback and did not result in any changes in the set of questions, items, or constructs. The questionnaire was used to gather data within a medium-sized city located in Europe between September and October 2009. We employed a multi-channel strategy 
to reach the respondents: We contacted 100 people via phone and 1500 via mail (both randomly chosen). Moreover, we placed additional 1,500 questionnaires at the cities' town-hall and local libraries. Potential respondents were assured of the confidentiality of their responses. Furthermore, we raffled three material prizes among all respondents. Thanks to an active involvement of the mayor our study found good coverage in the local media. Thus, we received 518 questionnaires (192 from respondents of age 50 or higher). An additional non-response analysis did not reveal any biases.

Data analysis phase. The structured data was first analysed using SPSS 17.0.0. Here, we selected only data records from respondents of age 50 or higher (senior citizens) which led to 192 cases. To further analyse our dataset, we employed the partial least squares (PLS) path modelling algorithm as it is suitable for data sets with lower than 200 cases $[35,38]$. The software package to support this was SmartPLS [41]. Except internet usage (formative measurement), all constructs were modelled using reflective indicators (cf. [47]; for a detailed discussion on formative versus reflective indicators, cf. [14]). The data used incorporates some missing values (Average of 2 per case). These missing values were treated using the mean replacement algorithm [1]. In the analysis phase we compared two different models, one without moderating effects and one with moderation through variables from the digital divide knowledge base. This data analysis procedure allows us to evaluate the above stated hypotheses.

Sample Demographics. Our sample consists of data of 192 senior citizens. The mean age of the respondents was slightly above 62. They spent on average 11.6 years in school or university which proves a decent education. Concerning gender, our sample is almost equally distributed $(51.56 \%$ were female). The income variable shows the most missing values (52). However, we can observe quite high incomes for the sample population (Table 1). Moreover, sample demographics show that the number of people with migration background is rather low. $98 \%$ of the respondents have the citizenship of the country studied and $97 \%$ are native speakers of the corresponding language. Hence, it is quite difficult to analyse any results related to migration background.

Table 1. Demographics of the analysed sample

\begin{tabular}{|c|c|c|c|c|c|}
\hline Question & $\mathbf{N}$ & Min & Max & Mean & Std. Dev. \\
\hline AGE (in years) & 192 & 50,00 & 83,00 & 62,3385 & 8,41371 \\
\hline EDU (in years of education) & 180 & 0 & 20 & 11.63 & 3.853 \\
\hline $\begin{array}{l}\text { INC }(0=\text { less than } 1000 € ; \\
1=\text { between } 1000 € \text { and } 2000 € ; \\
2=\text { between } 2000 € \text { and } 3000 € ; \\
3=\text { more than } 3000 €)\end{array}$ & 140 & 0 & 3 & 1,83 & ,952 \\
\hline
\end{tabular}

\section{Results}

We will present our results derived using the above mentioned methodology in a three-stepped approach. First, we will study the validity of our constructs (outer 
model) using standardised measures [7,46,47]. Second, we will present the inner model: the paths and their coefficients in both models (with and without moderating digital divide variables). Third, we will present and compare the coefficient of determination of both models.

Outer Model. We measured the internal consistency reliability (ICR) of all latent variables using Cronbach's Alpha. Generally, an ICR above .9 is considered as excellent, one between .7 and .9 as high, one between .5 and .7 as moderately high, and one between .5 as low [30]. The reliabilities in the presented study are comparably high, only social influence is in the high moderate area. The high ICRs show that the items measure the corresponding construct. All correlations between the constructs were lower than the square roots of the shared variance between the constructs and their measures in every case. According to Fornell and Larker [25] this supports convergent and discriminant validity. ${ }^{2}$ We employed a bootstrapping method (500 iterations) using randomly selected sub-samples to the significance of our PLS model. Analysing the item loadings, we could generally observe that our latent variables are measured by the corresponding items. All items except PE4 and FC4 have comparably high item loadings (Table 2). However, analysing the average variance extracted in all cases shows that our constructs can be considered valid [30].

Table 2. Item Loadings (with moderator effect - significance of items is stable)

\begin{tabular}{|c|c|c|c|c|c|}
\hline LV & Item & Loading & $\mathbf{L V}$ & Item & Loading \\
\hline \multirow{4}{*}{ tri } & PE1 & $.8910^{* * *}$ & \multirow{3}{*}{$\bar{a}$} & BI1 & $.9301 * * *$ \\
\hline & PE2 & $.8190 * * *$ & & $\mathrm{BI} 2$ & $.8323 * * *$ \\
\hline & PE3 & $.7681 * * *$ & & $\mathrm{BI} 3$ & $.9235 * * *$ \\
\hline & PE4 & $.3629 * * *$ & \multirow{11}{*}{ 尧 } & USE01INFO & .5894 \\
\hline \multirow{4}{*}{ 空 } & EE1 & $.8473^{* * *}$ & & USE02COMM & .2515 \\
\hline & EE2 & $.8244 * * *$ & & USE03BUSI & .1113 \\
\hline & EE3 & $.8142 * * *$ & & USE04BANK & .1475 \\
\hline & EE4 & $.7042 * * *$ & & USE05HEAL & .0582 \\
\hline \multirow{4}{*}{$\bar{s}$} & SI1 & $.6820 * * *$ & & USE06TOUR & .0829 \\
\hline & SI2 & $.5839 * * *$ & & USE07GOVE & .0556 \\
\hline & SI3 & $.5977 * * *$ & & USE08EDUC & .0217 \\
\hline & SI4 & $.7666^{* * * *}$ & & USE09SOCI & .0147 \\
\hline \multirow{4}{*}{$\bigcup_{I}$} & FC1 & $.8779 * * *$ & & USE10GAME & -.0678 \\
\hline & $\mathrm{FC} 2$ & $.8835^{* * * *}$ & & USE_PRI_MINPERW & .0744 \\
\hline & FC3 & $.8887 * * *$ & \multirow{2}{*}{$\stackrel{b}{g}$} & LANGUAGE & $.9507 * * *$ \\
\hline & FC4 & $.2518^{*}$ & & NATIONALITY & $.9530 * * *$ \\
\hline
\end{tabular}

a) USE was measured in a formative way, therefore we present the corresponding weights.

b) Education, Income, and Gender were measured with one variable.

Inner Model. In the first model without moderator effects (UTAUT), all paths have to be proven significant using the bootstrapping method (Table 3). We observed a high influence of Performance Expectancy on Behavioural Intention and of

\footnotetext{
${ }^{2}$ Data for the measurement model estimation can be found in the Appendix for review purposes only.
} 
Behavioural Intention on USE. The other path coefficients are comparably low. However, as the analysis suggests that every considered path is correct, we did not drop any for the second model with moderator effects.

In the second model (UTAUT and digital divide variables), several relationships were moderated by education, gender, income, and migration background. By this, 16 interaction terms were added to the analysis. The moderator variable migration background was added; however, as the sample population shows almost no migration background the related results are not interpretable. Bootstrapping suggests that only a minority of all paths used is significant. This is due to the high amount of moderating constructs in the model and can be ignored [47]. However, some path coefficients are high and will be further analysed in the discussion section.

Table 3. Path Coefficients

\begin{tabular}{|c|c|c|c|c|c|}
\hline \multicolumn{3}{|c|}{ Dependent Variable: BI } & \multicolumn{3}{|c|}{ Dependent Variable: USE } \\
\hline & \begin{tabular}{|l|} 
without \\
moderator \\
effects
\end{tabular} & $\begin{array}{l}\text { with } \\
\text { moderator } \\
\text { effect }\end{array}$ & & \begin{tabular}{|l} 
without \\
moderator \\
effects
\end{tabular} & \begin{tabular}{|l|} 
with \\
moderator \\
effect
\end{tabular} \\
\hline $\mathrm{R}^{2}$ & .5181 & .6378 & $\mathrm{R}^{2}$ & .7120 & .7440 \\
\hline $\mathrm{PE}$ & $.4651 * * *$ & .0867 & BI & $.7065^{* * * *}$ & $.6469 * * *$ \\
\hline $\mathrm{EE}$ & $.2106 * *$ & .3892 & FC & $.1770 * *$ & .1274 \\
\hline SI & $.1947 * * *$ & .2223 & EDU & & -.0243 \\
\hline EDU & & $-.2678 *$ & GEN & & -.2206 \\
\hline GEN & & .1682 & INC & & .0320 \\
\hline INC & & -.0519 & MIG & & -.0679 \\
\hline MIG & & -.0741 & FC*EDU & & .1265 \\
\hline PE*EDU & & $.6236^{*}$ & FC*GEN & & $.3307 *$ \\
\hline PE*GEN & & -.0502 & FC*INC & & .0471 \\
\hline PE*INC & & .0394 & FC*MIG & & -.1191 \\
\hline $\mathrm{PE} * \mathrm{MIG}$ & & .0989 & & & \\
\hline EE*EDU & & -.2068 & & & \\
\hline EE*GEN & & .1472 & & & \\
\hline EE*INC & & .0536 & & & \\
\hline EE*MIG & & -.1460 & & & \\
\hline SI*EDU & & .1354 & & & \\
\hline SI*GEN & & -.1956 & & & \\
\hline SI*INC & & -.0600 & & & \\
\hline SI*MIG & & -.0736 & & & \\
\hline
\end{tabular}

Coefficient of Determination. The coefficient of determination $\left(\mathrm{R}^{2}\right)$ is defined as the proportion of variability in the data explained by the statistical model (and not by random error terms or not included constructs). The original UTAUT achieved an $\mathrm{R}^{2}$ for BI between .51 and .77 and for USE between .41 and .52 [47]. Our analysis already shows a high coefficient of determination of .5181 for BI and .7120 for USE in the first model without moderating effects. In the second case with moderating 
effects we can even observe higher $\mathrm{R}^{2}$-Values for both BI (.6378) and USE (.7440). Thus, the model combining UTAUT and Digital Divide is able to explain more of the variance in usage behaviour of senior citizens (Table 3).

\section{Discussion}

Outer Model. As shown above, all constructs are valid which is in line with the theoretical foundation. However, the UTAUT-originating construct Social Influence has an ICR of .59. This is only considered moderately high by Hinton et al. [30]. Further theory development could try to find better fitting items, for instance by including items from the Model of Adoption of Technology in Households [8].

Inner Model and Hypotheses. The results for the paths' coefficients of the inner model can be mapped with the hypotheses mentioned in section 3. Especially the path coefficient of the moderating digital divide variables are of high interest.

- The expected performance of internet usage is the main driver for elderly citizens. With the highest path coefficient of all, performance expectancy has high influence on the internet usage. Therefore, governments aiming at an inclusive information society should evaluate their e-inclusion t-governmental strategies with special regards to raising the positive expectations of senior citizens. Thus, our analysis confirms hypothesis H1a. The influence of Performance Expectancy on Behavioural Intention is highly positive moderated by education. Especially for higher educated seniors the expected performance is a good predictor for the intention to use the internet. Other moderator variables provide only marginal powers of explanation. Hence, our analysis partially confirms hypothesis H1b.

- The influence of Effort Expectancy is overestimated. Although Effort Expectancy does significantly influence Behavioural Intention in a high positive way, it is not among the main drivers for internet usage. Apparently, Effort Expectancy is overestimated as its influence is not as high as expected. However, the analysis partially approved our hypothesis H2a. The relationship between Effort Expectancy and Behavioural Intention is moderated by education and gender. On the one hand, especially for less educated people, the expected effort is of high importance for their Behavioural Intention. On the other hand, the same fact holds true for men. The influence of other moderator variables is low. Therefore, our analysis partially validates the hypotheses $\mathrm{H} 2 \mathrm{~b}$.

- Social factors influence Behavioural Intention. The impact of Social Influences on Behavioural Intention is comparable to the one of Effort Expectancy. Thus, hypothesis $\mathrm{H} 3 \mathrm{a}$ can be regarded as partially confirmed. Moreover, our analysis shows that especially women are influenced by their social milieu with the path coefficient for the corresponding moderator variable at -.1956. The second moderator variable influencing the importance of social factors is education. Highly educated senior citizens are more influenced by their social setting than less educated ones. Thus, hypothesis $\mathrm{H} 3 \mathrm{~b}$ can be regarded as partially confirmed.

- The influence of Behavioural Intention on actual internet usage is high. In both models tested, the influence of the intention to use on the actual use is both high and significant. Thus, we can regard the hypothesis $\mathrm{H} 4$ as proven. 
- Facilitating Conditions is not the main driver for internet usage. Our analysis provides evidence that the impact of Facilitating Conditions on actual usage is not as high as expected. Material access as part of facilitating conditions is neither the only nor the main driver for internet usage as the corresponding path coefficient is the lowest of all construct related path coefficients in the whole model (ad H5a). However, the impact of Facilitating Conditions is highly moderated by education and gender. Apparently, especially for well educated men, facilitating conditions are crucial for internet usage.

Model Comparison. Both presented models explain the variance of private internet use significantly. Our quantitative analysis shows that the fusion of UTAUT and Digital Divide constructs provides great value in predicting both the intention to use and the use of the internet in a private manner. We can show that a model that integrates both approaches is better than a model building on the original UTAUTconstructs only. However, the UTAUT has to be proven as valuable for predicting private internet usage.

Our results bear several implications for practice. Today's local government use ICT to lever their organisation and processes to a more effective and efficient level in terms of e-government or t-government. However, to make their ICT supported governmental services accessed by everyone they need to bridge the digital divide.

- As Performance Expectancy is the main driver for behavioural intention to use the internet local authorities should think about the communication and marketing of benefits of internet usage in general and the usage of ICT supported governmental services (t-government) in special to elderly citizens. Here, especially more educated citizens can be reached.

- So far, a lot of courses to provide the right skill set to elderly citizens have been initiated or supported by local governments. However, the study shows that the influence of Effort Expectancy is comparably low. Authorities should evaluate their undertakings in terms of computer courses and especially focus on less educated persons.

- Decision makers should also think about working on the social environment of their inhabitants and, e.g. address strong disseminators enrooted in the corresponding milieu. One idea would be to train local opinion leaders to use the internet and give them the opportunity to talk about their path to becoming "experts" on the local radio.

- The silver bullet of local governments to bridge the digital divide has been to provide internet access to excluded groups. However, our study suggests that this approach is outdated: Material access as part of facilitating conditions is neither the only nor the main driver for internet usage. The corresponding path coefficient is the lowest of all construct related path coefficients in the whole model. Apparently, pure material access is not the crucial factor any more. Local authorities should therefore rethink their engagements in this direction in order to make their ICT supported services used by everyone. 


\section{Conclusion}

This paper examines influencing factors for senior citizens' use of the internet for private purposes. We present a research model and develop a corresponding questionnaire based on technology acceptance and digital divide research. Our 2009 survey yields 192 responses from senior citizens (age $50 \mathrm{yrs}$ and above). The resulting dataset was analysed using PLS path modelling [41]. Our results suggest that UTAUT is particularly useful for analysing private internet usage achieving an $\mathrm{R}^{2}$ as high as .7120. We also found that the main driver for senior citizens internet usage is performance expectancy: The higher the expected performance or utility, the higher the intention to use the internet. Drawing from digital divide research, we extended the UTAUT-model by four additional variables that are hypothesised to mediate original UTAUT-relationships. Including interaction terms, we observed that e.g. especially for women the social influence through their corresponding milieu is extremely important and that men are more influenced by the facilitating conditions. All in all, our extended model is able to explain as much as $74 \%$ of the variation in internet usage and, therefore, is better than the original UTAUT model for this specific purpose. We thus provide evidence that the inclusion of digital divide constructs yields greater explanatory power than UTAUT constructs only.

However, our study is beset with certain limitations. First, the total population studied did not include many people with migration background (only 3\% of the respondents). Therefore, we could not well interpret the results on the influence of this specific variable. Moreover, our study was carried out in a specific region in Western Europe. We believe that our results will, to a great extent, hold true in other settings as well. Future research could aim at testing this assumption by carrying out a comparable study in other national/social/cultural settings. In addition, longitudinal studies could show the development of private internet usage and its influencing factors among senior citizens over time and could thus be regarded another potentially fruitful avenue for future research. Other future research could cover the matching of existing local government e-inclusion projects with the given explaining variables: Which projects contribute to performance or effort expectancy, how is social influence stimulated and how can facilitating conditions be improved? Which projects address the needs of specific groups (see digital divide variables) best? Such overview, we believe, could be very valuable but does not yet exist to our knowledge. As for future theory development, we were able to explain the largest share of variance in private internet usage among senior citizens by employing nine variables, taken from technology acceptance and digital divide research. Here, we believe, further testing of influencing factors, for instance psychological variables (e.g., the Big Five, cf. [12]) could still increase explanatory power.

\section{References}

1. Afifi, A.A., Elashoff, R.M.: Observations in Multivariate Statistics: I. Review of the Literature. Journal of the American Statistical Association 61(315), 595-604 (1966)

2. Agerwal, R., Animesh, A., Prasad, K.: Social Interactions and the "Digital Divide": Explaining Variations in Internet Use. Information Systems Research 20(2), 277-294 (2009) 
3. Al-Shafi, S., Weerakkody, V.: Understanding Citizens' Behavioural Intention in the Adoption of E-Government Services in the State of Qatar. In: European Conference on Information Systems, Verona, Italy (2009)

4. Becker, J., Niehaves, B., Bergener, P., Fielenbach, K., Räckers, M., Weiß, B.: The Digital Divide in E-Government - A Quantitative Analysis. In: Proceedings of the IADIS International Conference e-Society, Algarve, Portugal, pp. 337-344 (2008)

5. Bélanger, F., Carter, L.: The Impact Of The Digital Divide On E-Government Use. Communications of the ACM 52(4), 132-135 (2009)

6. Brandtweiner, R., Donat, E.: Digital Divide in Austria - Any Reasons for Enthusiasm? The Case of Austria. In: Proceedings of the 20th Bled eConference - eMergence: Merging and Emerging Technologies, Processes and Institutions, Bled Slovenia, June 3-6 (2007)

7. Brown, S.A., Venkatesh, V.: Model of Adoption of Technology in Households: A Baseline Model Test and Extension Incorporating Household Life Cycle. MIS Quarterly 29(3), 399-426 (2005)

8. Brown, S.A., Venkatesh, V., Bala, H.: Household technology Use: Integrating Household Life Cycle and the Model of Adoption of Technology in Households. The Information Society 22, 205-218 (2006)

9. Cabinet Office: Transformational Government - Enabled by Technology. Strategy Document, London, UK (2005)

10. Cabinet Office: Transformational Government - Implementation Plan, London, UK (2006)

11. Compeau, D.R., Higgins, C.A., Huff, S.: Social Cognitive Theory and Individual Reactions to Computing Technology: A Longitudinal Study. MIS Quarterly 23(2), 145-158 (1999)

12. Costa, P.T., McCrae, R.R.: Revised NEO Personality Inventory (NEO-PI-R) and NEO Five-Factor Inventory (NEO-FFI) professional manual. Psychological Assessment Resources, Odessa (1992)

13. Davis, F.D.: Perceived usefulness, perceived ease of use, and user acceptance of information technology. MIS Quarterly 13(3), 319-339 (1989)

14. Diamantopoulos, A., Siguaw, J.A.A.: Formative versus Reflective Indicators in Organizational Measure Development: A Comparison and Empirical Illustration. British Journal of Management 17(4), 263-282 (2006)

15. Duff, A.S., Craig, D., McNeill, D.A.: A note on the origins of 'information society'. Journal of Information Science 22(5), 122-171 (1996)

16. Eastman, J.K., Iyer, R.: The elderly's uses and attitudes towards the internet. Journal of Consumer Marketing 21(3), 208-220 (2004)

17. EHEMU: Are we living longer, healthier lives in the EU? European Health Expectancy Monitoring Unit Technical report 2, Montpellier, France (2005),

http://www.hs.le.ac.uk/reves/ehemutest/pdf/techrep20507.pdf

18. European Commission: eInclusion@EU: Strengthening eInclusion \& eAccessibility across Europe. Analytic framework - eInclusion and eAccessibility priority issues (2004a)

19. European Commission: The impact of ageing on public expenditure: projections for the EU 25 Member States on pensions, health care, long-term care, education and unemployment transfers (2004-2005), European Commission, Brussels (2006)

20. European Commission: Top of the web. User Satisfaction and Usage Survey of E-Government services, Kopenhagen (2004b)

21. European Union: Riga Ministerial Declaration (2006), http://ec.europa.eu/information_society/events/ict_riga_2006/ doc/declaration_riga.pdf 
22. Ferro, E., Gil-Garcia, J.R., Helbig, N.: The Digital Divide Metaphor: Understanding Paths to IT Literacy. In: Wimmer, M.A., Scholl, J., Grönlund, Å. (eds.) EGOV 2007. LNCS, vol. 4656, pp. 265-280. Springer, Heidelberg (2007)

23. Fishbein, M., Ajzen, I.:: Belief, attitude, intention, and behaviour : An introduction to theory and research. Addison-Wesley Pub. Co., Reading (1975)

24. Fishbein, M.: Attitude and the prediction of behaviour. In: Fishbein, M. (ed.) Readings in attitude theory and measurement, pp. 477-492. Wiley, New York (1967)

25. Fornell, C., Larker, D.F.: Evaluating Structural Equation Models with Unobservable Variables and Measurement Error: Algebra and Statistics. Journal of Marketing Research 18(3), 382-388 (1981)

26. Fougère, M., Mérette, M.: Population ageing and economic growth in seven OECD countries. Economic Modelling 16, 411-427 (1999)

27. Gilly, M.C., Enis, B.M.: Recycling the Family Life Cycle: A Proposal for Redefinition. Advances in Consumer Research 9, 271-276 (1982)

28. Hauser, P.M., Duncan, O.D.: The Study of Population. An Inventory and Appraisal, Chicago (1959)

29. Henseler, J., Fassott, G.: Testing Moderating Effects in PLS Path Models: An Illustration of Available Procedures. In: Handbook of Partial Least Squares: Concepts, Methods and Applications in Marketing and Related Fields. Springer, Heidelberg (2009)

30. Hinton, P.R., Brownlow, C., McMurvay, I., Cozens, B.: SPSS explained. Routledge Inc., East Sussex (2004)

31. Irani, Z., Elliman, T., Jackson, P.: Electronic transformation of government in the U.K.: a research agenda. European Journal of Information Systems 16, 327-335 (2007)

32. Kiel, J.: The digital divide: Internet and e-mail use by the elderly. Medical Informatics \& the Internet in Medicine 30(1), 19-23 (2005)

33. Kraner, S.: Bridging the Digital Divide in E-Government, Zürich (2004)

34. Machlup, F.: The Production and Distribution of Knowledge in the United States. Princeton University Press, Princeton (1962)

35. Marcoulides, G.A., Chin, W.W., Saunders, C.: A Critical Look at Partial Least Squares Modeling'. MIS Quarterly 33(1), 171-175 (2009)

36. Milner, H.: UK online centres: Transformational Government for the Citizen. Research report, Sheffield, UK (2009)

37. Moore, G.C., Benbasat, I.: Development of an Instrument to Measure the Perceptions of Adopting an Information Technology Innovation. Information Systems Research 2(3), 192-222 (1991)

38. Morgan, S.P., Hagewen, K.J.: Handbook of Population (2006)

39. Niehaves, B., Becker, J.: The Age-Divide in E-Government - Data, Interpretations, Theory Fragments. In: Proceedings of the 8th IFIP Conference on e-Business, e-Services, and e-Society (I3E 2008), Tokyo, Japan, pp. 279-287 (2008)

40. Population Reference Bureau: World Population Data Sheet 2006, Washington, DC (2006), http: / /www.prb.org/pdf06/06WorldDataSheet.pdf

41. Ringle, C.M., Wende, S., Will, S.: SmartPLS 2.0 (M3) Beta, Hamburg (2005), http: / / www. smartpls.de

42. Smith, P.: A Blueprint for Transformation. E-Government Bulletin (2006),

http://www.cio.gov.uk/documents/news/pdf /

ABlueprintForTransformation.pdf

43. Taylor, S., Todd, P.A.: Understanding Information Technology Usage: A Test of Competing Models. Information Systems Research 6(4), 570-591 (1995) 
44. Thompson, R.L., Higgins, C.A., Howell, J.M.: Personal Computing: Toward a Conceptual Model of Utilization. MIS Quarterly 15(1), 124-143 (1991)

45. van Dijk, J.A.G.M.: Digital divide research, achievements and shortcomings. Poetics 34(4-5), 221-235 (2006)

46. Venkatesh, V., Brown, S.A., Maruping, L.M., Bala, H.: Predicting Different Conceptualizations of System Use: The Competing Roles of Behavioural Intention, Facilitating Conditions, and Behavioural Expectation. MIS Quarterly 32(3), 483-502 (2008)

47. Venkatesh, V., Morris, M.G., Davis, G., Davis, F.: User Acceptance of Information Technology: Toward a Unified View. MIS Quarterly 27(3), 425-478 (2003)

48. Wagner, J., Hanna, S.: The Effectiveness of Family Life Cycle Variables in Consumer Expenditure Research. Journal of Consumer Research 10, 281-291 (1983) 